\title{
Medical versus surgical treatment of a primary tuberculous pleural peel
}

\author{
Richard Long $M D^{1}$, Anne Fanning $\mathrm{MD}^{1}$, Ciaran McNamee $\mathrm{MD}^{2}$, \\ James Barrie $\mathrm{MD}^{3}$, Lakshmi Puttagunta $\mathrm{MD}^{4}$
Departments of ${ }^{1}$ Medicine, ${ }^{2}$ Surgery, ${ }^{3}$ Radiology and ${ }^{4}$ Pathology, \\ University of Alberta Hospitals, Edmonton, Alberta
}

\begin{abstract}
R Long, A Fanning, C McNamee, J Barrie, L Puttagunta. Medical versus surgical treatment of a primary tuberculous pleural peel. Can Respir J 2001;8(6):449-453.
\end{abstract}

The role and timing of surgical decortication in the management of a primary tuberculous pleural peel remains controversial. The present report describes the case of a young man with an extensive primary tuberculous pleural peel that responded dramatically to medical therapy. A serious attempt at surgical decortication three weeks into antituberculous drug therapy may have removed some compressive aspects of the peel, facilitating lung expansion. However, it had almost no measurable impact on the size of peel and was technically very difficult. Response to treatment was measured anatomically (computed tomography scans) and physiologically (pulmonary function tests).

Key Words: Tuberculous pleural peel

\section{Primo-infection tuberculeuse et capsule pleu- rale : traitement médical ou traitement chirurgical?}

RÉSUMÉ : Le rôle et le moment de la décortication chirurgicale pour le traitement d'une capsule pleurale d'origine tuberculeuse primaire fait toujours l'objet de controverse. Voici le cas d'un jeune homme porteur d'une grosse capsule pleurale secondaire à une primo-infection tuberculeuse, qui a remarquablement bien réagi au traitement médical. Une tentative sérieuse de décortication chirurgicale accompagnée d'un traitement médicamenteux antituberculeux de trois semaines aurait pu permettre la résection de certains éléments compressifs de la capsule et faciliter ainsi l'expansion pulmonaire, mais l'intervention n'a pratiquement eu aucune incidence mesurable sur la taille de la capsule et s'avérait extrêmement délicate sur le plan technique. La réaction au traitement a été mesurée anatomiquement à l'aide de la tomodensitométrie et physiologiquement à l'aide de l'exploration fonctionnelle respiratoire.
$\mathrm{W}$ hen tuberculous pleurisy complicates primary infection, it is generally believed to be the result of the contiguous spread of localized pulmonary inflammation across the visceral pleura as delayed-type hypersensitivity evolves (1-4). Left untreated, primary tuberculous effusions usually resolve spontaneously. Thereafter, however, they are associated with an extraordinarily high risk of reactivation tuberculosis $(5,6)$. Less commonly, a primary tuberculous pleural effusion may develop in association with miliary or disseminated tuberculosis complicating primary infection (4). In this setting, the pathogenesis of the effusion may be diffuse infection of the pleura rather than a delayed-type hypersen- sitivity reaction (7). For reasons that are not well understood but perhaps are related to delayed presentation, some tuberculous pleural effusions have organized and encased the ipsilateral lung by the time of presentation.

The management of a patient presenting with a large primary tuberculous pleural peel is controversial. Should they be treated with medical therapy alone or both medically and surgically, and if surgery is recommended, when should it be performed? Some suggest that decortication is required only in rare instances of long-standing large volume effusions that have resulted in markedly thickened pleura and trapped lung, with substantial physiological impairment (4). 

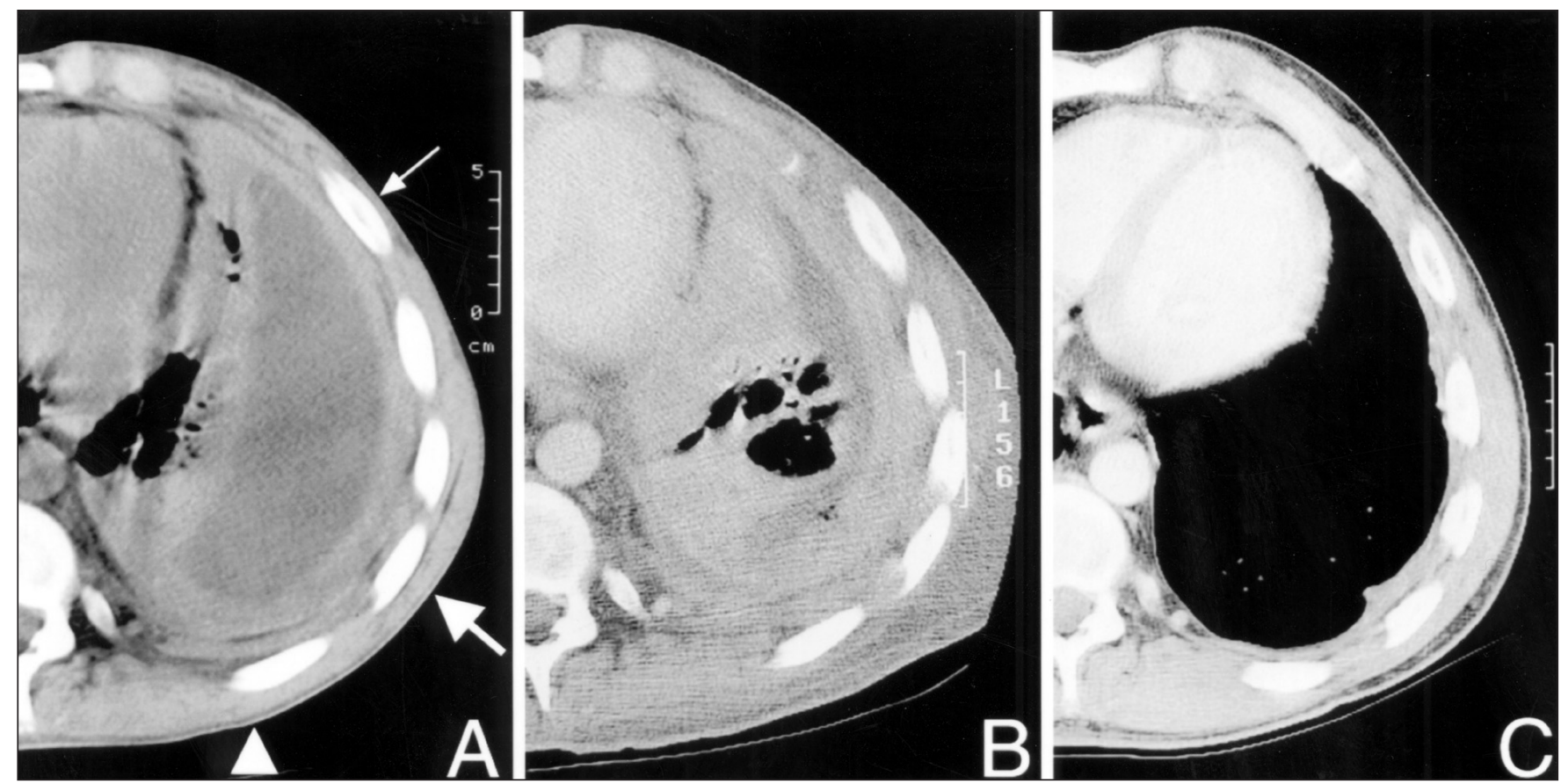

Figure 1) Serial computed tomography images from A November 18, 1999, B December 23, 1999 and $\mathbf{C}$ August 25, 2000 at the level of the lower thorax (upper aspect of $T_{11}$ ) showing the extent of the pleural peel over the course of treatment. Parietal peel thickness (at the completion of treatment, it was combined visceral plus parietal) was recorded as the mean $\pm S D$ of three measurements (A): at the anterior axillary line (thin arrow), the posterior axillary line (thick arrow) and perpendicular to the posterior chest wall (arrowhead)

As well, that surgical intervention should be deferred until antituberculous drug therapy has diminished the mycobacterial burden and reduced the chances of infection at the operation sites - probably a matter of six to eight weeks of medication. Others suggest that pleural thickening decreases with treatment, so that decortication should not be considered until the patient has undergone medical treatment for at least six months (3). Needless to say, these approaches are somewhat variant, and though many may favour a long period of medical treatment before considering surgical decortication, we could find no good documentation of 'pharmacological' decortication in the literature. The infrequency with which medical specialists and thoracic surgeons are now faced with this problem adds further to the uncertainty about how to proceed (8). In the present paper, the case of a large tuberculous pleural peel, managed both medically and surgically, is presented; the response to each treatment modality was carefully documented.

\section{CASE PRESENTATION}

A 19-year-old aboriginal man was admitted to hospital on November 18, 1999 with a history of left chest pain of one month's duration, and fatigue, night sweats and weight loss of two weeks' duration. He had no history of tuberculosis or antituberculous drug use. He had no history of underlying illness, denied intravenous drug abuse and was subsequently determined to be seronegative on repeated human immunodeficiency virus testing. He had received Bacille CalmetteGuérin vaccination in his first year of life, and had had a negative tuberculin test in 1992 and a normal chest radi- ograph in 1998. He lived in a relatively remote northern native community that had recently reported an outbreak of tuberculosis. A two-step tuberculin test in February 1999 was negative, and a specimen of sputum collected at that time was negative for acid-fast bacilli (AFB) on smear and culture. On October 20, 1999, during a subsequent community screening, another specimen of sputum was collected and determined to be smear-negative but culture-positive for Mycobacterium tuberculosis. A chest radiograph revealed a large left pleural effusion and/or peel and miliary nodules scattered diffusely throughout his lungs.

On admission, he was breathing rapidly and shallowly (30 breaths/min) but was not distressed. His temperature was $37.4^{\circ} \mathrm{C}$. Dullness to percussion and decreased breath sounds were present over the left hemithorax. A room air arterial blood gas test revealed a partial pressure of arterial oxygen of $82 \mathrm{mmHg}$ and a partial pressure of carbon dioxiode in arterial gas of $34 \mathrm{mmHg}$ (difference in partial pressures of oxygen in mixed alveolar gas and mixed arterial blood $\left[\mathrm{A}-\mathrm{aDO}_{2}\right] 12 \mathrm{mmHg}$ ). A tuberculin test was positive with $30 \mathrm{~mm}$ of induration. A computed tomography (CT) scan of the thorax revealed a large left pleural effusion with a moderately thick visceral and parietal pleural peel encasing the left lung (Figure 1A). At its thinnest, the parietal peel alone was 4 $\mathrm{mm}$; at its thickest, it was $19 \mathrm{~mm}$. Miliary nodules unassociated with co-existent cavitary or pneumonic disease were present throughout the lungs. Enlarged prevasular lymph nodes were present in the mediastinum. A slightly cloudy, straw-coloured exudate was found at thoracentesis on November 19, 1999. Tests on pleural fluid showed the fol- 


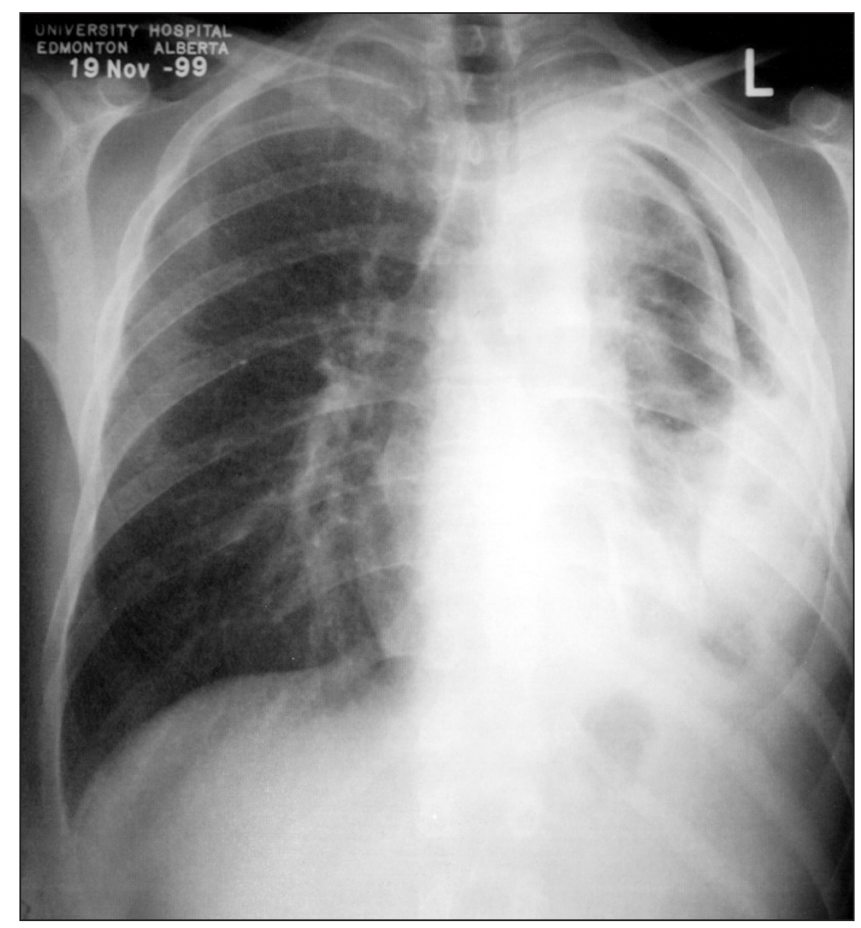

Figure 2) A post-thoracocentesis chest radiograph performed on November 19, 1999 revealed a large pleural space without lung expansion. Marked thickening of the parietal and, to a lesser extent, the visceral pleura is evident. L Left side of the hemothorax

lowing levels: protein $70 \mathrm{~g} / \mathrm{L}$, lactate dehydrogenase 2424 $\mathrm{U} / \mathrm{L}$, glucose less than $0.3 \mathrm{mmol} / \mathrm{L}$, cell count $4100 \times 10^{6} / \mathrm{L}$ with $98 \%$ polymorphonuclear leukocytes and $\mathrm{pH} 7.09$ (coincident arterial blood $\mathrm{pH}$ 7.43). Acid-fast smears of pleural fluid were negative, but cultures were ultimately positive for $M$ tuberculosis. All stains and cultures for nonmycobacterial pathogens were negative. A post-thoracentesis chest radiograph revealed a large pleural space without lung expansion (Figure 2). Spirometry showed a moderately severe restrictive defect (Table 1). Antituberculous drugs were started on November 19, 1999 - isoniazid $300 \mathrm{mg}$, rifampin $600 \mathrm{mg}$, pyrazinamide $1500 \mathrm{mg}$ and ethambutol $1600 \mathrm{mg}$ daily.

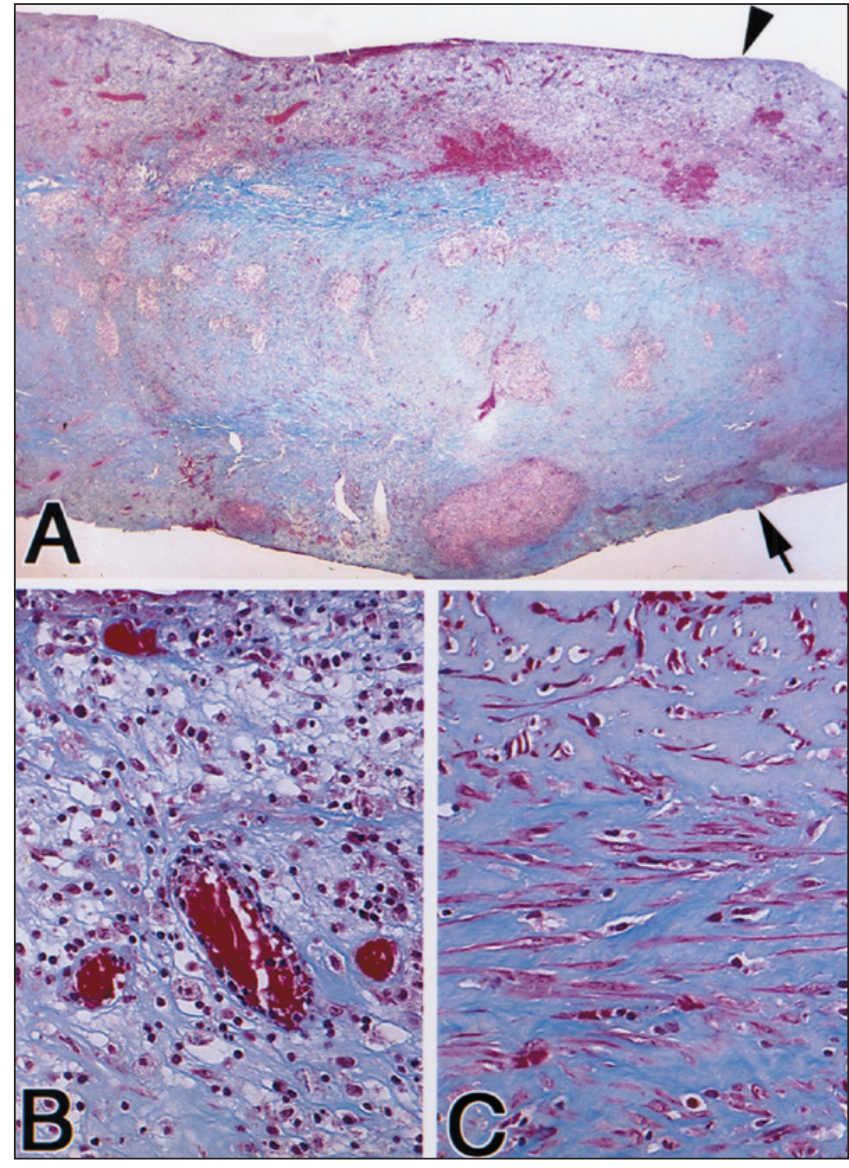

Figure 3) Masson's trichrome stain of the parietal pleural peel resected on December 9, 1999. At low power (A original magnification $\times 15$ ) the tissue is seen to consist of approximately $50 \%$ loose stroma at the margins of the pleural cavity (arrowhead) and chest wall (arrow), and 50\% collagen (blue stain) at a deeper level. Neovessels and granulomata are plentiful in the loose stroma and collagen layers, respectively. Higher power views (original magnification $\times 250$ ) of the stromal and collagen layers are presented in $\mathbf{B}$ and $\mathbf{C}$

After much discussion on how best to manage his pleural disease, a decision was made to proceed with decortication to prevent lung entrapment and possible late sequelae of a

\section{TABLE 1}

Serial CT scan and lung function test results in a patient with a primary tuberculous pleural peel

\begin{tabular}{|c|c|c|c|c|c|c|c|c|c|c|}
\hline \multirow[b]{2}{*}{ Study date } & \multirow{2}{*}{\multicolumn{3}{|c|}{$\begin{array}{c}\text { Thickness of the parietal } \\
\text { pleural peel at CT scan }(\mathrm{mm})^{*}\end{array}$}} & \multirow[b]{2}{*}{ Study date } & \multicolumn{6}{|c|}{ Pulmonary function } \\
\hline & & & & & $\begin{array}{c}\text { FEV }_{1} \\
\text { (\% pred) }\end{array}$ & $\begin{array}{c}\text { FVC } \\
\text { (\% pred) }\end{array}$ & $\begin{array}{c}\text { TLC } \\
\text { (\% pred) }\end{array}$ & $\begin{array}{c}\text { DCO } \\
\text { (\% pred) }\end{array}$ & $\begin{array}{c}\mathrm{PaO}_{2} \\
(\mathrm{mmHg})\end{array}$ & $\begin{array}{c}\mathrm{PaCO}_{2} \\
(\mathrm{mmHg})\end{array}$ \\
\hline November 18, 1999 & $5.7 \pm 0.6$ & $6.3 \pm 2.5$ & $9.3 \pm 3.1$ & November 21, 1999 & 63 & 63 & - & - & 82 & 34 \\
\hline- & - & - & - & November 29, 1999 & 57 & 55 & - & - & - & - \\
\hline December 23, 1999 & $7.3 \pm 3.2$ & $10.2 \pm 3.5$ & $14.3 \pm 2.9$ & December 24, 1999 & 68 & 67 & - & - & - & - \\
\hline- & - & - & - & February 1, 2000 & 75 & 71 & - & - & - & - \\
\hline August $25,2000^{\ddagger}$ & $0.0 \pm 0.0$ & $2.5 \pm 0.9$ & $1.7 \pm 2.9$ & August 28, 2000 & 107 & 107 & 102 & 91 & 88 & 40 \\
\hline
\end{tabular}

Surgery was performed on December 9, 1999. *Mean ( \pm SD) of three measurements of the thickness of the parietal pleural peel: anterior axillary line, posterior axillary line and perpendicular to the posterior chest wall (Figure 1); ${ }^{\dagger}$ Upper thorax: $T_{5-6}$ intervertebral disc, mid-thorax: upper aspect of $T_{8}$, lower thorax: upper aspect of $T_{11} ;{ }^{\ddagger}$ At this measurement time, the recorded thickness is that of the visceral plus parietal pleura combined. CT Computed tomography; DCO Diffusing capacity; FEV Forced expiratory volume in 1 s; FVC Forced vital capacity; PaO ${ }_{2}$ Partial pressure of oxygen in arterial blood; $\mathrm{PaCO}_{2}$ Partial pressure of carbon dioxide in arterial blood; Pred Predicted; TLC Total lung capacity 
destroyed lung. On December 9, 1999, after an unremarkable bronchoscopy, a fifth intercostal, serratus-sparing posterolateral thoracotomy was performed. A thick pleural rind was encountered. An attempt was made to remove both the visceral and parietal components of this rind, with emphasis on the visceral component. However, the surgery was complicated by increased pleural vascularity and a tenacious adherence of the peel to the underlying lung. It was impossible to free the mediastinal and diaphragmatic surfaces because of danger to the underlying vascular structures. Thus, the decortication was limited to the upper and lateral aspect of the pleural space. At histopathology, the pleural tissue was rich in neovessels. Superficially, there was a loose, immature cellular stroma beneath which lay a more organized connective tissue layer containing large granulomata (Figure 3). Special stains were positive for AFB. Mixed type 1 and type 2 collagen was shown on immunohistochemical study. A repeat CT thorax on December 23, 1999 documented the continued presence of the peel (Figure 1B). In fact, between this scan and the baseline scan performed five weeks earlier, all measurements of the thickness of the parietal peel had increased 3 to $6 \mathrm{~mm}$, except for measurements taken at the anterior and posterior axillary line of the upper thorax. These had remained the same. Spirometry confirmed the persistence of a restrictive defect (Table 1).

The isolate of $M$ tuberculosis proved to be susceptible to all first-line drugs. Ethambutol was discontinued after one month, pyrazinamide after two months, and isoniazid and rifampin after nine months. All treatment was directly observed. At the completion of treatment, a CT scan and pulmonary function test showed nearly $100 \%$ resolution of the pleural peel (Figure 1C), and complete normalization of lung function, including an $\mathrm{A}-\mathrm{aDO}_{2}$ of $3 \mathrm{mmHg}$ (Table 1).

\section{DISCUSSION}

We have presented the case of a young, otherwise healthy man with an extensive primary tuberculous pleural peel who responded dramatically to medical therapy. A serious attempt at surgical decortication three weeks into antituberculous drug therapy may have removed some compressive aspects of the peel, facilitating lung expansion. However, it had almost no measurable effect on the size of the peel and technically was very difficult.

The size of the peel and the physiological abnormality associated with it, as well as the miliary lung disease, were measured serially at the outset, five weeks into therapy (two weeks post-thoracotomy for decortication) and at the completion of chemotherapy. Parietal peel thickness was measured on CT scans at the anterior axillary line, posterior axillary line and perpendicular to the posterior chest wall. Each of these measurements was made at the upper, middle and lower thorax at each of the above times. Between the first and second CT scans (Table 1), all measurements of peel thickness had increased by 3 to $6 \mathrm{~mm}$ except for those measurements taken at the anterior and posterior axillary line of the upper thorax, where the partial surgical decortication had been undertaken. This increase in the thickness of the peel between the first and second CT scans may have been related to the surgery and associated edema. Against this were the preoperative fall in vital capacity observed during the first nine days of chemotherapy and the increase in all measurements of peel thickness at the lower thorax (Figure 1), where the surgeon had not been working. Thus, some progression of the peel may have occurred during the first five weeks of medical treatment. Thereafter, it slowly resolved, such that all that remained after 'pharmacological' decortication was minimal residual focal pleural thickening (combined visceral plus parietal) and normal lung function.

The decision to proceed with surgical decortication in this young man could be disputed. Weighing in its favour were the following.

First, this was a young, otherwise well patient with moderately severe lung restriction, potentially reversible with decortication.

Second, there was an unsatisfactory understanding of the relative contribution to the restrictive defect of the pleural process and the miliary interstitial disease (9).

Third, the absence of associated fibrocavitary lung disease on radiological studies (10) and the normal $\mathrm{A}-\mathrm{aDO}_{2}$ at baseline, despite the restrictive defect, suggested that underlying lung function was intact. Restoration of lung function after surgical decortication is closely related to the absence of pre-existing parenchymal disease (11).

Fourth, the possibility that antituberculous drugs may not penetrate the pleural process. Subtherapeutic levels of antituberculous drugs, with the development of acquired resistance, have been reported in the setting of a chronic tuberculous empyema (12). Though our patient did not have a tuberculous empyema, as defined by gross pus in the pleural space with AFB readily visible on stain (7), the extent of the peel and the inability to predict medical responsiveness in similar cases left the question of drug access open. In Stead et al's (1) original series, only two of 15 patients appeared to respond to an average of four months of isoniazid and streptomycin. In a more recent series (13), two of eight patients with tuberculous empyema and peel failed to respond to a combination of four-drug medical therapy, tube thoracostomy and repeated installation of a fibrinolytic agent. Documentation of radiographic and physiological responses in the medical successes was not provided. Tuberculous effusions without empyema or pleural peel and due to fully susceptible isolates have been shown to respond satisfactorily to six months of isoniazid and rifampin (14).

Fifth, adjunctive corticosteroids have not been shown to have a favourable effect on tuberculous pleurisy-associated fibrogenesis (15).

Our case would seem to suggest that a primary tuberculous pleural peel in a patient with relatively intact lungs, who is receiving standard, fully supervized antituberculous drug therapy for a fully susceptible isolate, should be fol- 
lowed up expectantly, because a good response to chemotherapy may be anticipated. It is probable that evidence of a relatively immature fibrotic and vascular pleural inflammatory reaction predicts a good response, whereas a more mature, organized reaction predicts a poor response to medical therapy alone. If the response to medical therapy fails, the maturation of the pleural process may define better planes of separation and reduce surgery-associated blood loss (16).

Regarding the genesis of the pleural peel in our patient, it is noteworthy that the proinflammatory cytokine tumour necrosis factor-alpha (TNF- $\alpha$ ) has been shown to be produced and selectively concentrated at the site of disease activity in patients with tuberculous pleuritis $(17,18)$. High levels of pleural fluid TNF- $\alpha$, and low levels of glucose and $\mathrm{pH}$ (the latter observed in our patient) have been correlated

\section{REFERENCES}

1. Stead WW, Eichenholz A, Strauss HK. Operative and pathological findings in twenty-four patients with the syndrome of idiopathic pleurisy with effusion presumably tuberculosis. Am Rev Tuberc 1955;71:473-502.

2. Abrams WB, Small MJ. Current concepts of tuberculous pleurisy as derived from pleural biopsy studies. Scand J Respir Dis 1960;38:605 .

3. Tuberculous pleural effusions. In: Light RW, ed. Pleural Diseases, 3rd edn. Baltimore: Williams and Wilkins, 1995:154-66.

4. Extrapulmonary tuberculosis in adults. In: Iseman MD. A Clinician's guide to tuberculosis. Baltimore: Lippincott Williams and Wilkins, 2000:145-97.

5. Patiala J. Initial tuberculous pleuritis in the Finnish Armed Forces in 1939-1945 with special reference to eventual post pleuritic tuberculosis. ACTA Tuberc Scand 1954;36(Suppl):1-57.

6. Roper WH, Waring JJ. Primary serofibrinous pleural effusion in military personnel. Am Rev Tuberc 1955;71:616-34.

7. Sahn SA, Iseman MD. Tuberculous empyema. Semin Respir Infect 1999; 14:82-7.

8. Treasure R, Seaworth BJ. Current role of surgery in Mycobacterium tuberculosis. Ann Thorac Surg 1995;59:1405-9.

9. Williams MH Jr, Yoo OH, Kane C. Pulmonary function in miliary tuberculosis. Am Rev Respir Dis 1973;107:858-60.

10. Long R, O'Connor R, Palayew M, Hershfield E, Manfreda J. Disseminated tuberculosis with and without a miliary pattern on chest radiograph: a clinical-pathologic-radiologic correlation. Int J Tuberc Lung Dis 1997;1:52-8.

11. Patton W, Watson T, Gaensler E. Pulmonary function before and at intervals after surgical decortication of the lung. Surg Gynecol Obstet 1952;95:477-96.

12. Elliott AM, Berning E, Iseman MD, Peloquin C. Failure of drug with the subsequent development of pleural fibrosis in treated patients (19). TNF- $\alpha$ has been shown to cause a significant increase in proliferation and collagen production (mainly type 1) by rat pleural mesothelial cells in vitro (20). Levels of the fibrinolysin, tissue-type plasminogen activator, correlate negatively with those of TNF- $\alpha$ in tuberculous effusions (21). Transforming growth factor-beta may also play a role in tuberculous pleurisy-associated fibrogenesis (22). The collagen deposited in our patient may account for the small residual pleural thickening seen at the completion of treatment.

ACKNOWLEDGEMENTS: The authors are very grateful to Dick Jones PhD for his review and Susan Falconer for her preparation of the manuscript. Dr Long was supported by University of Alberta Trust Account \#790 1050. penetration and acquisition of drug resistance in chronic tuberculous empyema. Tuberc Lung Dis 1995;76:463-7.

13. Al-Kattan KM. Management of tuberculous empyema. Eur J Cardiothorac Surg 2000;17:251-4.

14. Dutt AK, Moers D, Stead WW. Tuberculous pleural effusion: 6-month therapy with isoniazid and rifampin. Am Rev Respir Dis 1992;145:1429-32.

15. Lee C-H, Wang W-J, Lan R-S, Tsai Y-H, Chiang Y-C. Corticosteroids in the treatment of tuberculous pleurisy. A double-blind, placebocontrolled, randomized study. Chest 1988;94:1256-9.

16. Thomas GI, Jarvis FJ. Decortication in primary tuberculous pleuritis and empyema with a study of functional recovery. J Thorac Surg 1956;32:178-89.

17. Barnes PF, Fong S-J, Brennan PJ, Twomey PE, Mazumder A, Modlin RL. Local production of tumor necrosis factor and interferon gamma in tuberculous pleuritis. J Immunol 1990;145:149-54.

18. Söderblom T, Nyberg P, Teppo A-M, Klockars M, Riska H, Pettersson T. Pleural fluid interferon- $\alpha$ and tumour necrosis factor- $\alpha$ in tuberculous and rheumatoid pleurisy. Eur Respir J 1996;9:1652-5.

19. de Pablo A, Villena V, Echove-Sustaeta J, Encuentra AL. Are pleural fluid parameters related to the development of residual pleural thickening in tuberculosis? Chest 1997;112:1293-7.

20. Owens MN, Grimes SR. Pleural mesothelial cell response to inflammation: tumor necrosis factor-induced mitogenesis and collagen synthesis. Am J Physiol 1993;265:L382-8.

21. Hua C-C, Chang L-C, Chen Y-C, Chang S-C. Proinflammatory cytokines and fibrinolytic enzymes in tuberculous and malignant pleural effusions. Chest 1999;116;1292-6.

22. Maeda J, Ueki N, Ohkawa T, et al. Local production and localization of transforming growth factor-beta in tuberculous pleurisy. Clin Exp Immunol 1993;92:32-8. 


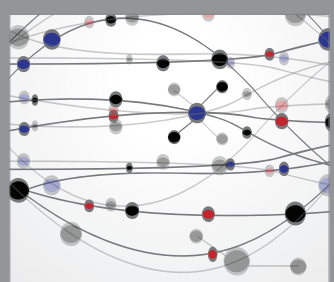

The Scientific World Journal
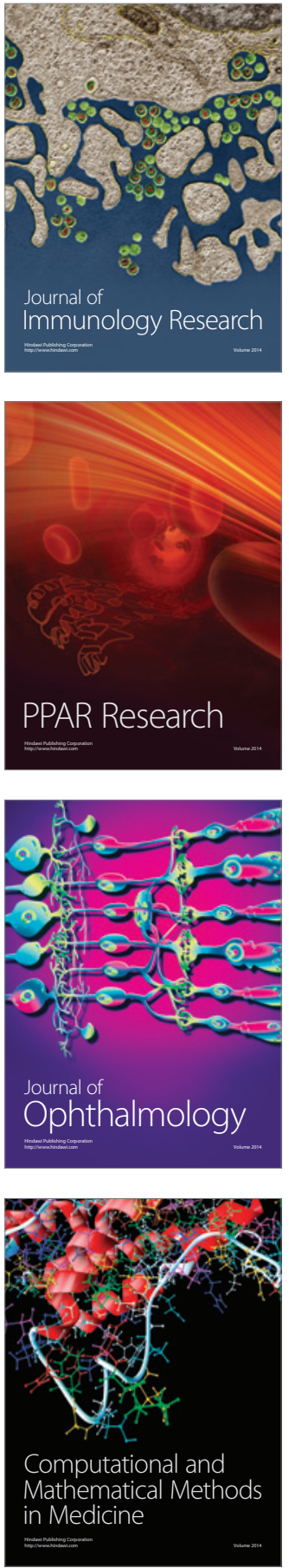

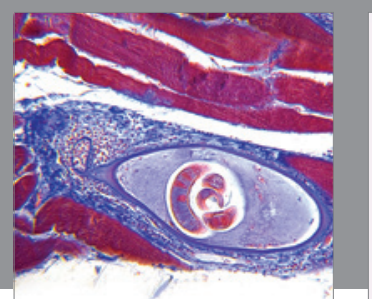

Gastroenterology Research and Practice

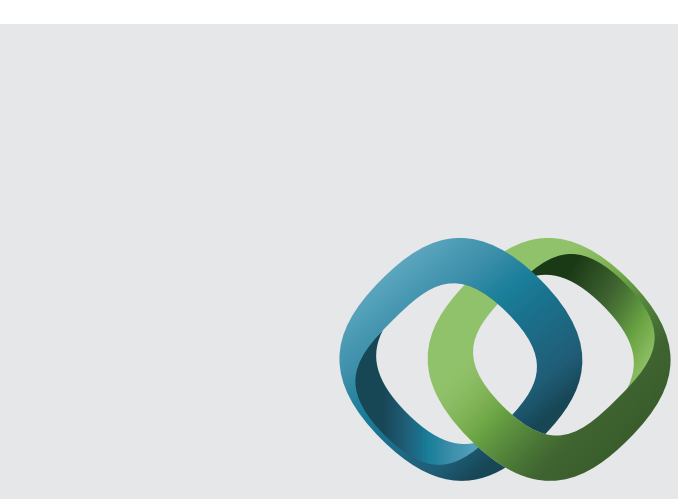

\section{Hindawi}

Submit your manuscripts at

http://www.hindawi.com
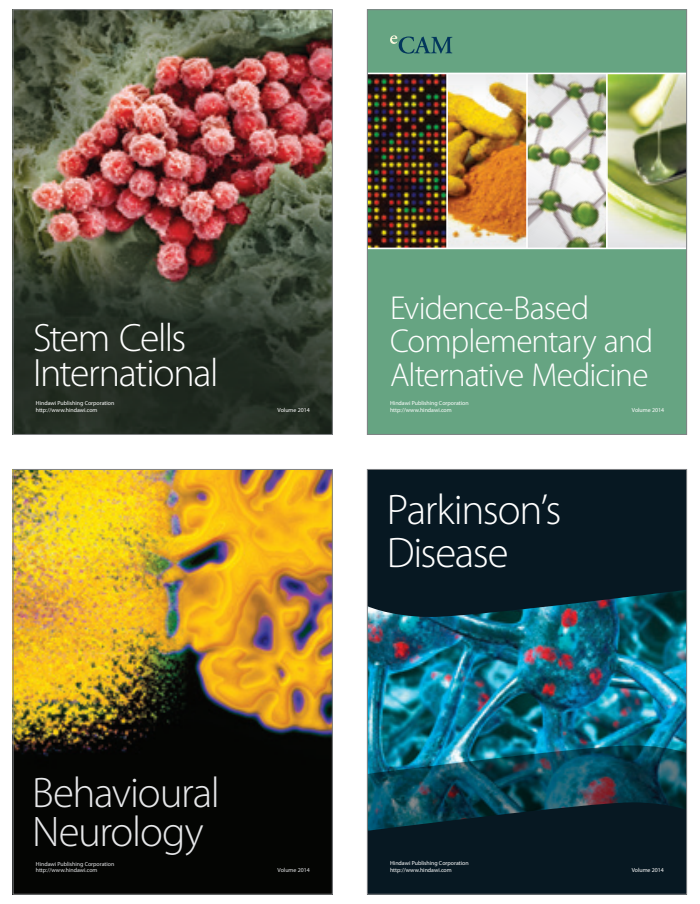
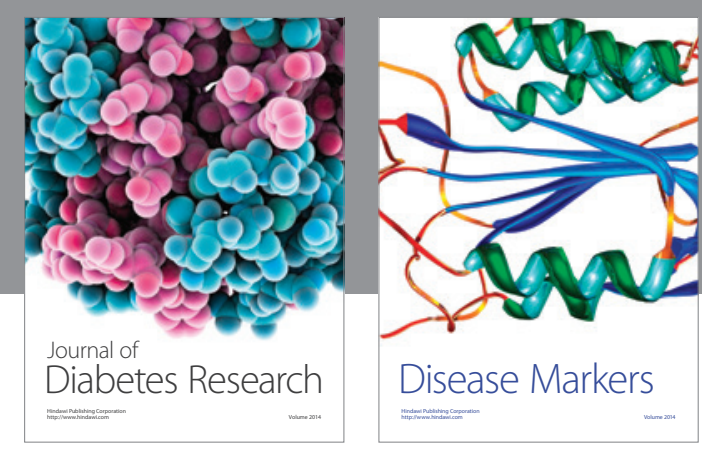

Disease Markers
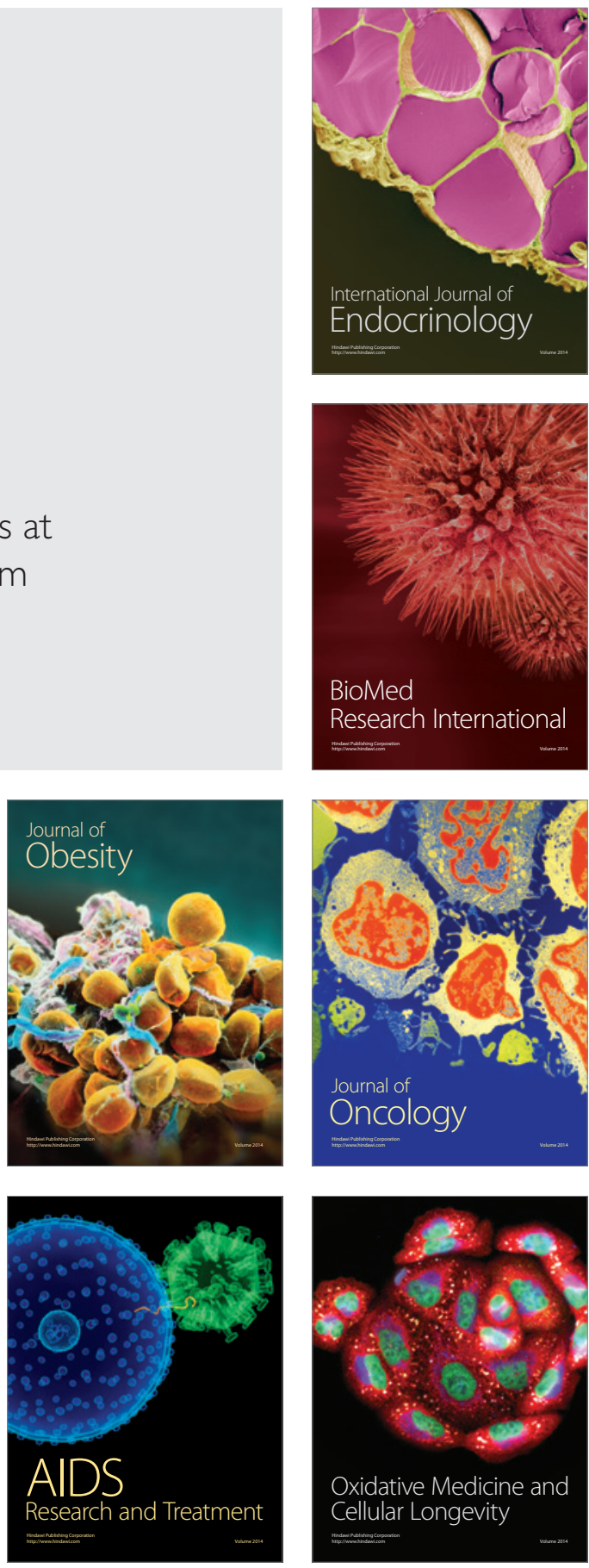